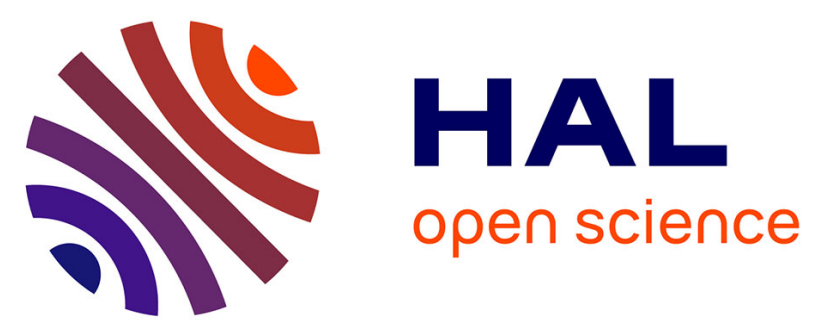

\title{
Influence of Substrate Temperature and Film Thickness on Thermal, Electrical, and Structural Properties of HPPMS and DC Magnetron Sputtered Ge Thin Films
} Andrej Furlan, Dario Grochla, Quentin d'Acremont, Gilles Pernot, Stefan Dilhaire, Alfred Ludwig

\section{To cite this version:}

Andrej Furlan, Dario Grochla, Quentin d'Acremont, Gilles Pernot, Stefan Dilhaire, et al.. Influence of Substrate Temperature and Film Thickness on Thermal, Electrical, and Structural Properties of HPPMS and DC Magnetron Sputtered Ge Thin Films. Advanced Engineering Materials, 2017, 19 (5), pp.1600854. 10.1002/adem.201600854 . hal-01539190

\section{HAL Id: hal-01539190 \\ https://hal.univ-lorraine.fr/hal-01539190}

Submitted on 16 Jan 2018

HAL is a multi-disciplinary open access archive for the deposit and dissemination of scientific research documents, whether they are published or not. The documents may come from teaching and research institutions in France or abroad, or from public or private research centers.
L'archive ouverte pluridisciplinaire HAL, est destinée au dépôt et à la diffusion de documents scientifiques de niveau recherche, publiés ou non, émanant des établissements d'enseignement et de recherche français ou étrangers, des laboratoires publics ou privés.

\section{(2)(1) $\$$}

Distributed under a Creative Commons Attribution - NonCommercial - ShareAlikel 4.0 


\title{
Influence of Substrate Temperature and Film Thickness on Thermal, Electrical, and Structural Properties of HPPMS and DC Magnetron Sputtered Ge Thin Films**
}

\author{
By Andrej Furlan, Dario Grochla, Quentin D'Acremont, Gilles Pernot, Stefan Dilhaire \\ and Alfred Ludwig*
}

Ge was deposited as thickness gradient films at temperatures up to $800^{\circ} \mathrm{C}$ by direct current (DC) and high power pulsed magnetron sputtering (HPPMS). Structural characterization shows increased crystallization with increasing substrate temperature and film thickness. Thermal conductivity was measured by a novel high throughput time domain thermo reflectance method. Thermo electrical properties correlate to the degree of crystallization. Conductivities increase with increasing substrate temperature up to $500^{\circ} \mathrm{C}$. For higher temperatures the trend reverses. A room temperature deposited/ annealed film displays smaller crystallites $(10 \mathrm{~nm})$ and lower thermal conductivity $\left(5 \mathrm{Wm}^{1}{ }^{1}{ }^{1}\right.$ ) compared to $25 \mathrm{Wm}^{1} \mathrm{~K}^{1}$ for hot DC deposition. Compared to DC, HPPMS films show higher thermal conductivities up to $45 \mathrm{Wm}{ }^{1} \mathrm{~K}^{1}$.

\section{Introduction}

Having a lower energy bandgap (0.67 eV@ $300 \mathrm{~K})$ compared to Si $(1.14 \mathrm{eV} @ 300 \mathrm{~K})$, and a significantly lower price compared to other low-bandgap III/V alloys, Germanium (Ge) in its pure form has advantages for applications in, for example, optoelectronic devices. ${ }^{[1]} \mathrm{Ge}$ is also a material of significant interest for thermo-photovoltaic applications, ${ }^{[2]}$ because of its bandgap energy matching the maximum emission spectrum for black body radiation for $T<2000 \mathrm{~K}$. There has been significant interest in Si Ge thermoelectric alloys, earliest reports on their

[*] Prof. Dr. A. Ludwig, Dr. A. Furlan, Dr. D. Grochla Institute for Materials, Ruhr-Universität Bochum, 44801 Bochum, Germany

E-mail: alfred.ludwig@rub.de

Q. D'Acremont, Prof. Dr. S. Dilhaire

Laboratoire Ondes et Matière d'Aquitaine (LOMA - UMR CNRS 5798), Université de Bordeaux, 33405 Talence, France Q. D'Acremont

Amplitude Systèmes, 11 Avenue de la Canteranne, Cité de la Photonique, 33600 Pessac, France

Dr. G. Pernot

Laboratoire d'Energétique et de Mécanique Théorique et Appliquée (LEMTA - UMR 7563), Université de Lorraine, 54518 Vandouvre-lès-Nancy, France

[**] The authors acknowledge funding from M-Eranet project ICETS (DFG LU1175/16-1) as well as from DFG SFB TR 87, project C2 (A.L., D.G). transport properties can be traced back more than 50 years, ${ }^{[3]}$ while in more recent times, the focus has been mainly on the bulk form. ${ }^{[4,5]}$ Based on recent theoretical investigations of transport properties in Si Ge structures, ${ }^{[6-8]}$ highly complex lattice structures could be formed to obtain optimal transport properties. By investigating structural and transport properties of pure Ge in the form of magnetron sputtered thin films, we take a step toward synthesis of multinary Ge-containing thin film thermoelectrics.

For applications in its elemental form, Ge is used almost exclusively in the form of either amorphous or polycrystalline thin film coatings of thickness ranging from few atomic layers to a few hundred nanometers, making the understanding of deposition parameters influence on film crystallization important. Studies on the crystallization properties of Ge began in the 1960's. ${ }^{[9,10]}$ These studies often refer to bulk material, or coatings deposited by methods, such as evaporation $^{[11]}$ or ion beam sputter deposition, ${ }^{[12]}$ and chemical vapor deposition. ${ }^{[13]}$ For applications requiring precision film deposition, compared to the previously mentioned deposition methods, magnetron sputtering offers the possibility of fine-tuning of deposition conditions, film composition, and uniformity of the as-deposited films, while keeping the process itself relatively simple. However, sputtering as a process is not in thermal equilibrium, and most atoms impinging on the surface with energies of in a range of few eV, undergo quenching of at rates of $>10^{6} \mathrm{~K} \mathrm{~s}^{-1}$. Such conditions can lead to amorphous thin films, and often 
deposited particles need to be given additional energy during the deposition process in order to form a crystalline structure. ${ }^{[14]}$ Since elemental Ge is a semiconductor that is typically amorphous in the form of thin films, ${ }^{[10]}$ the right choice of deposition parameters is critical. By remaining partially or completely in the amorphous form, the transport properties of $\mathrm{Ge}$ thin films can be significantly altered compared to the crystalline material bulk properties, mainly due to the influence of phonon mean free path. ${ }^{[15]}$ Differently to bulk Ge, the thickness of thin films can be, depending on the degree of crystallization, comparable to the electron and phonon mean free path, which, can influence significantly the electrical conductivity of the material. ${ }^{[16]}$

In order to optimize the electrical and thermal conductivity of Ge films for thermoelectric applications, a systematic study of the influence of deposition parameters on film structure and, indirectly, on film transport properties was performed. In this work, the influence of substrate temperature $\left(T_{S}\right)$, annealing conditions, and film thickness on the crystallization properties of pure Ge thin films as determined by X-ray diffraction (XRD) and scanning electron microscopy (SEM), are investigated. We detect the range of deposition conditions that produce films ranging from completely amorphous to polycrystalline structures with crystallite sizes $>100 \mathrm{~nm}$. The possible influence of the film thickness on transport properties and crystallization is investigated. For high $T_{s}$, microstructural grains detected by SEM are much larger than coherent reflexive domains (crystallites) calculated by the Scherrer equation. The electrical and thermal conductivities of the films are related to the crystallization properties and deposition parameters, for both direct current (DC) and high power pulsed magnetron sputtering (HPPMS).

\section{Experimental Section}

\subsection{Deposition of Ge Thin Films}

Ge thin films were deposited in a vacuum chamber with a base pressure of mid $10^{-6} \mathrm{~Pa}$ range from a single, powerregulated, $100 \mathrm{~mm}$ cathode in a $3.75 \mathrm{mTorr}(0.5 \mathrm{~Pa})$ pure $\mathrm{Ar}$ atmosphere with a $40 \mathrm{sccm}$ gas flow rate. An elemental target of polycrystalline Ge $(99.999 \%$, Sindlhauser Materials $\mathrm{GmbH}$ ) was used. The films were deposited on ribbonshaped fused silica substrates $(80 \times 10 \mathrm{~mm})$. In order to achieve a thickness gradient, the substrates were positioned facing the cathode with their narrower sides, the cathode (target) being inclined by $28^{\circ}$ relative to the substrate plane. The distance between the target and the center of the substrate table was $14 \mathrm{~cm}$. The bias voltage was kept at the floating potential during all depositions. The films were deposited in batches by DC and HPPMS sputter processes, respectively. For the power-controlled DC deposition process, a constant power of $200 \mathrm{~W}$ was applied to the target. For the HPPMS deposition process, a pulsed bias with maximum voltage of $920 \mathrm{~V}$, a peak current of $100 \mathrm{~A}$, and a pulse width of $60 \mu$ s were applied. The pulse repetition frequency was $100 \mathrm{~Hz}$, resulting in a duty ratio of $0.6 \%$, and a peak power of $92 \mathrm{~kW}$. The deposition time for all samples was $4 \mathrm{~h}$, with a deposition rate for DC sputtering at the center of the ribbons of around $0.19 \mathrm{~nm} \mathrm{~s}^{-1}$.

For a simultaneous deposition at different $T_{S}$, a special step heater was used ${ }^{[17]}$ : Ge films were deposited simultaneously on five substrates held at five different temperatures between 200 and $800^{\circ} \mathrm{C}$ with steps of $150^{\circ} \mathrm{C}$. In addition, a single $\mathrm{Ge}$ film was deposited at room temperature by DC sputtering, using the same parameters as mentioned before, and subsequently annealed at $500{ }^{\circ} \mathrm{C}$ for $2 \mathrm{~h}$.

\subsection{Characterization of Ge Thin Films}

The degree of crystallization and structural properties of the Ge thin films were examined by XRD in Bragg-Brentano geometry. The measurements were carried out in a PanAnalytical $X^{\prime}$ Pert diffractometer using a $\mathrm{Cu} \mathrm{K} \alpha$ radiation source operating at $45 \mathrm{kV}$ and $40 \mathrm{~mA}\left(0.0131^{\circ}\right.$ step in a $2 \theta$ range of $2580^{\circ}$, time per step $61.2 \mathrm{~s}$ ). For the XRD amorphous samples, deposited at $T_{S}$ of $200{ }^{\circ} \mathrm{C}$, the amorphicity of the structure was additionally verified by synchrotron grazing-incidence diffraction at Beamline 9 of the DELTA synchrotron facility at the University of Dortmund, ${ }^{[18]}$ (radiation wavelength $0.06199 \mathrm{~nm}$, incidence beam angle $2^{\circ}$ ). The film structure was assessed from SEM images of film cross-sections obtained by the cleavage of the substrate along its length, while the film surface structural properties were examined by surface SEM images. Grain sizes at the film surface were determined directly from SEM film surface images using SEM image analysis software Image.${ }^{[19]}$ Because of the highly irregular shape of the grains, their sizes are presented according to three definitions: "bounding rectangle" gives size of the smallest rectangle the shape fits in, the "line intersection method" (LIM) consisting of counting the number of grains along straight lines of known length across the image and "Ferret's diameter", which gives the largest distance between two points on the shape boundary, giving thus, when compared to the values obtained by the two previously mentioned methods, an indication of grain shapes. The film thickness variation along the length of the sample was determined by SEM from the film cross-section. The thickness was measured at the extreme points of the substrate for all films assuming a linear variation in between. This assumption was verified by measuring thickness at three additional points for several samples. All SEM imaging was performed using a LEO 1530 microscope (Zeiss, Germany), operating at $1020 \mathrm{keV}$ acceleration voltage using the In-lens detector mode.

High-throughput electrical resistance measurements of the films were performed using a custom built highthroughput test stand, equipped with a 4-point probe head with spring-loaded contact pins with inter-pin distance of $0.5 \mathrm{~mm} .^{[20]}$ The resistance was measured at 21 spots along the sample length with a distance between spots of $3.75 \mathrm{~mm}$. 
Thermal conductivity measurements were performed using a novel High-throughput Time-Domain Thermo-reflectance (HT-TDTR) technique developed to carry out rapid thermal property measurements. This optical pump-probe technique combines both high-speed time acquisition of the heterodyned pump-probe laser system ${ }^{[21]}$ and a high sensitivity to thermal properties by modulating the pump laser beam and monitoring the phase (or equivalently a ratio signal) of the thermal signal. ${ }^{[22]}$ This unique experimental setup reduces the acquisition time of the TDTR signal by a factor of 5 compared to classical TDTR systems. The pump-probe delay is obtained by synchronizing two femtosecond lasers with a minor difference in their repetition rates $(76 \mathrm{MHz} \pm 0.25 \mathrm{~Hz})$, while the pump beam is modulated at $10 \mathrm{MHz}$. This modulation frequency offers a good trade-off between signal-to-noise ratio and sensitivity to thermal properties.

As required by the thermo-reflectance method, an $\mathrm{Al}$ layer with a thickness of $70 \mathrm{~nm}$ was deposited on the top surface of the samples prior to the measurements. This metallic transducer plays the double role of a heat source by absorption of the incoming laser pulse, and temperature probe through the change of reflectivity monitored by the second laser pulse. The light wavelength $(\approx 800 \mathrm{~nm})$ and metal type $(\mathrm{Al})$ were chosen to link directly the temporal decay of the reflectivity of the metal layer to its temperature. The optical signal recorded by a fast photodiode (Thorlabs DET10A) is filtered by a lock-in amplifier (Stanford SR844) giving a ratio signal (-real part/ imaginary part) used to identify both thermal conductivity and thermal boundary resistance between the metal and the Ge layer. The fitting procedure uses a Levenberg-Marquardt algorithm to minimize the difference between the experimental signal and a 3-dimensional heat transfer model with two free parameters (thermal conductivity and thermal boundary resistance).

\section{Results}

\subsection{Crystallization Assessment by XRD}

Figure 1 shows $X$-ray diffractograms for films deposited by DC and HPPMS sputtering at different $T_{S}$. All diffractograms shown were taken at the substrate ends with the thickest parts of the films. For both deposition methods, films deposited at $T_{S}=200^{\circ} \mathrm{C}$ are XRD amorphous. The amorphicity of those samples was further verified by grazing incidence X-ray diffraction (GIXD) using synchrotron radiation. For $T_{S}=350^{\circ} \mathrm{C}$ and above, films deposited by both deposition methods display clear and narrow standard diffraction peaks for the crystalline Ge structure with reflection indices (111), (220), (311), (440), (311), respectively, for increasing $2 \theta$ angle. As shown in Table 1, the full width at half maximum (FWHM) values for the most intense peaks for each diffractogram decreases with increasing $T_{S}$. Figure $2 \mathrm{a}$ and $\mathrm{b}$ show the variation of the crystallite sizes with the film thickness along the substrate strip, for Ge films deposited by DC sputtering and HPPMS, respectively. Sizes of the crystallites are determined from the (220) diffraction peak, which is the most

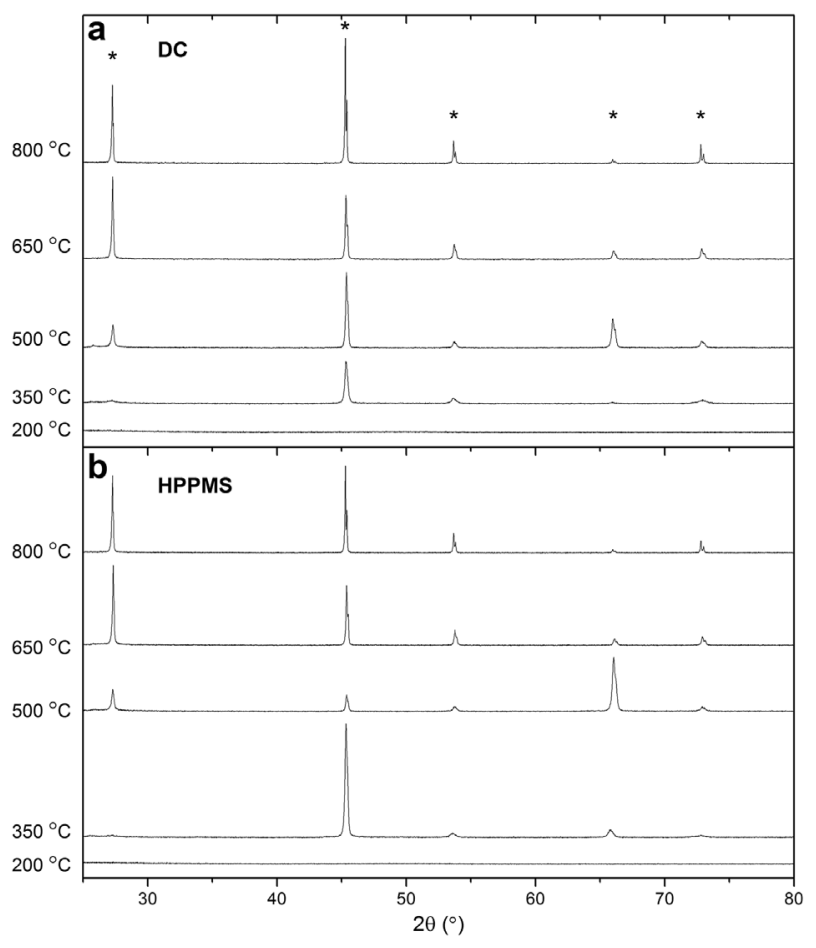

Fig. 1. XRD patterns for the DC (a) and HPPMS (b) deposited samples for five different substrate temperatures. Stars indicate (111), (220), (311), (400), (331) Ge peaks, respectively, with the increasing angle.

intense peak for most of the samples, and calculated as coherent reflective domains using the Scherrer equation, Equation 1,

$D=\frac{\lambda}{\left(\beta_{2 \theta} \cos \theta_{0}\right)}$

where $\lambda$ is $\mathrm{X}$-ray wavelength, $\beta_{2 \theta}$ is diffraction peak full width at half-maximum (FWHM), and $\theta_{0}$ is the Bragg angle at peak centroid. By increasing $T_{S}$ from 200 to $350{ }^{\circ} \mathrm{C}$, films deposited by HPPMS crystallize for all deposited thicknesses. On the other hand, as seen from Figure 2a for the DC sputtered films, for $T_{S}=350^{\circ} \mathrm{C}$, crystallites appear only for film thicknesses $>1.5 \mu \mathrm{m}$. For lower thicknesses the film at that $T_{S}$ is XRD amorphous. For $T_{S}=500^{\circ} \mathrm{C}$ and higher all films display, a crystalline structure with crystallite sizes increasing with increasing $T_{S}$ and increasing film thickness. Crystallite sizes for both deposition methods are similar at each $T_{S}$. For both deposition methods, and for all $T_{S}$, there is a trend for

Table 1. XRD peaks width at the half of their maximum intensity (FWHM) dependence on $T_{S}$ for DC and HPPMS deposited Ge films.

\begin{tabular}{lcc} 
Temperature $\left[{ }^{\circ} \mathrm{C}\right]$ & $\begin{array}{c}\text { FWHM DC } \\
{\left[{ }^{\circ}\right] / h k l}\end{array}$ & $\begin{array}{c}\text { FWHM HPPMS } \\
{\left[{ }^{\circ}\right] / h k l}\end{array}$ \\
\hline 200 & amorphous & amorphous \\
350 & $0.202[220]$ & $0.163[220]$ \\
500 & $0.134[220]$ & $0.192[111]$ \\
650 & $0.078[111]$ & $0.085[111]$ \\
800 & $0.073[220]$ & $0.075[220]$
\end{tabular}



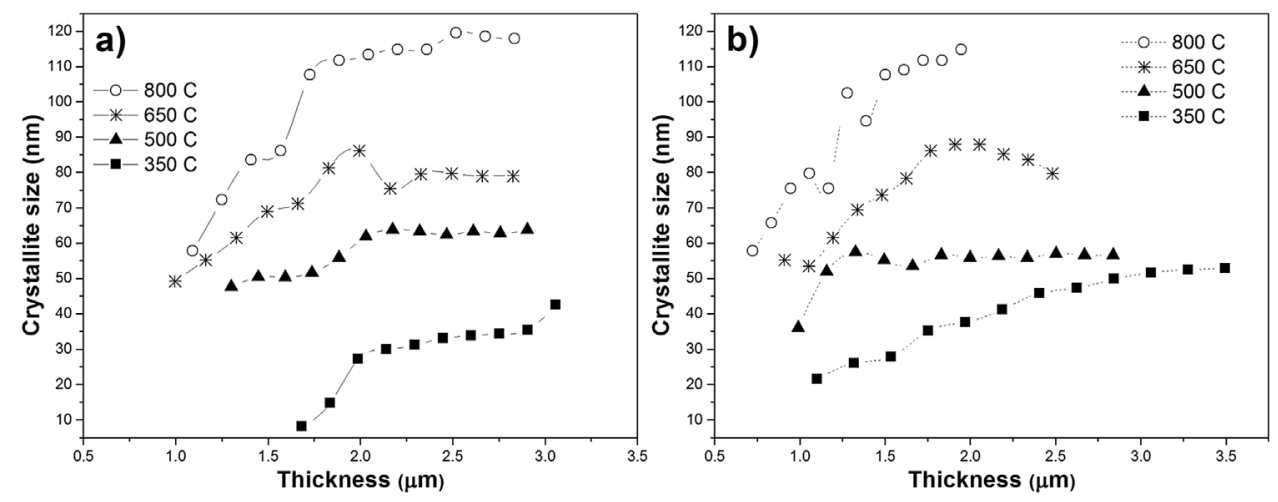

Fig. 2. Crystallite sizes determined by the Scherrer method for different $T_{S}$ and film thicknesses for Ge thin films deposited by (a) DC and (b) HPPMS sputtering.

crystallite size to plateau after a certain thickness. This tendency is particularly pronounced for DC sputtered films for which leveling of values can be observed at film thicknesses $>2 \mu \mathrm{m}$ for all $T_{S}$.

Figure 3 shows a comparison of the crystallite sizes in relation to film thickness, between a film deposited at $T_{S}=500^{\circ} \mathrm{C}$ and one deposited at $T_{S}=25^{\circ} \mathrm{C}$ and then annealed at $500^{\circ} \mathrm{C}$ for $150 \mathrm{~min}$. As in the case of the films deposited on a hot substrate, the annealed film displays a crystallite size increase with increasing thickness. For the overlapping thicknesses of the hot deposited and annealed films, crystallite sizes of the annealed film are smaller by more than a factor of two compared to the hot-deposited films. The small size of crystallites of the annealed sample indicates that the film structure is probably "locked" during deposition in an energetically relatively favorable configuration. As a consequence, a major structural rearrangement would necessitate annealing at a temperature of at least $800^{\circ} \mathrm{C}$. That makes such an approach impractical due to the incompatibility of such

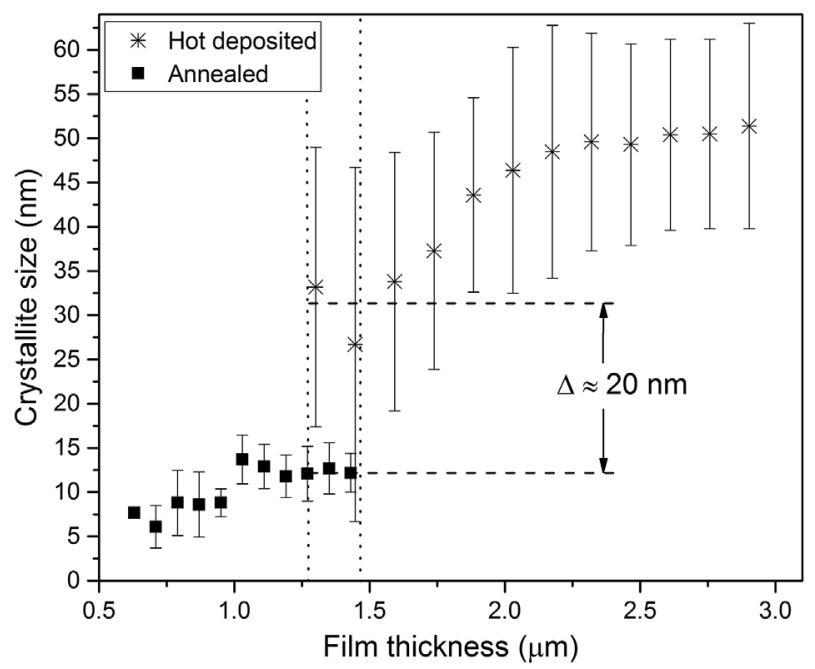

Fig. 3. Comparison of crystallite sizes for different film thickness of Ge films deposited at $T_{S}=500^{\circ} \mathrm{C}$, calculated from (111), (220), and (440) peaks, and deposited at $T_{S}=25^{\circ} \mathrm{C}$, and subsequently annealed at $500^{\circ} \mathrm{C}$ for $1.5 \mathrm{~h}$, calculated from (111), (220), and (311) peaks. The large error bars indicate significant difference in size for different crystalline directions. high processing temperatures with most practical applications. This confirms that, for low deposition temperatures, the amorphous form of Ge thin films is stable. The large difference in film crystallization for various $T_{S}$ indicates that Ge film structure formation is actually more dependent on the depositing atom's thermal mobility on the surface, rather than on the bombarding ion and depositing atom energy differences between DC and HPPMS. This effect of significant crystallinity increase with increasing $T_{S}$ was reported earlier for vapor-deposited Ge thin films. ${ }^{[11]}$ However, one should keep in mind that in thin films, intrinsic stress can be more pronounced closer to the substrate, due to lattice mismatch. ${ }^{[23,24]}$ This can cause broadening of the FWHM of the diffraction peaks, but becomes less pronounced when the film is thicker. Although peak broadening due to stress could theoretically influence values for crystallite sizes obtained from the Scherrer equation, this can be safely assumed to be negligible due to the very approximate nature of the Scherrer equation itself. ${ }^{[25]}$ In the investigated cases, it is expected that due to the film thicknesses of up to $3 \mu \mathrm{m}$, high $T_{S}$, and high annealing temperature most of the intrinsic stresses are relaxed. Thermal stresses can though remain present. From the differences of coefficients of thermal expansion for Ge and fused silica, it can be estimated that thermal stresses in the films arise to a range between 0.13 and $0.57 \mathrm{GPa}$. Such macrostresses in the polycrystalline films can be present mainly on the crystalline boundaries, or cause diffraction peaks shift. Broadening of the diffraction peaks due to such stresses is considered to be less likely. ${ }^{[26,27]}$

\subsection{SEM Determination of Film Microstructure}

The cross-sectional SEM images of the investigated Ge films are shown on Figure 4 for DC (top row) and HPPMS (bottom row) deposition methods, deposited simultaneously at five different $T_{S}$. For $T_{S}=200^{\circ} \mathrm{C}$ for both deposition methods the cross-section images display smooth surfaces with no visible structural details. This corresponds to the diffraction analysis data, which showed amorphous structure for the same $T_{S}$. For $T_{S}=350^{\circ} \mathrm{C}$, the images show a granular structure that indicates some amount of crystallization. For the HPPMS deposited film, this effect is more pronounced 


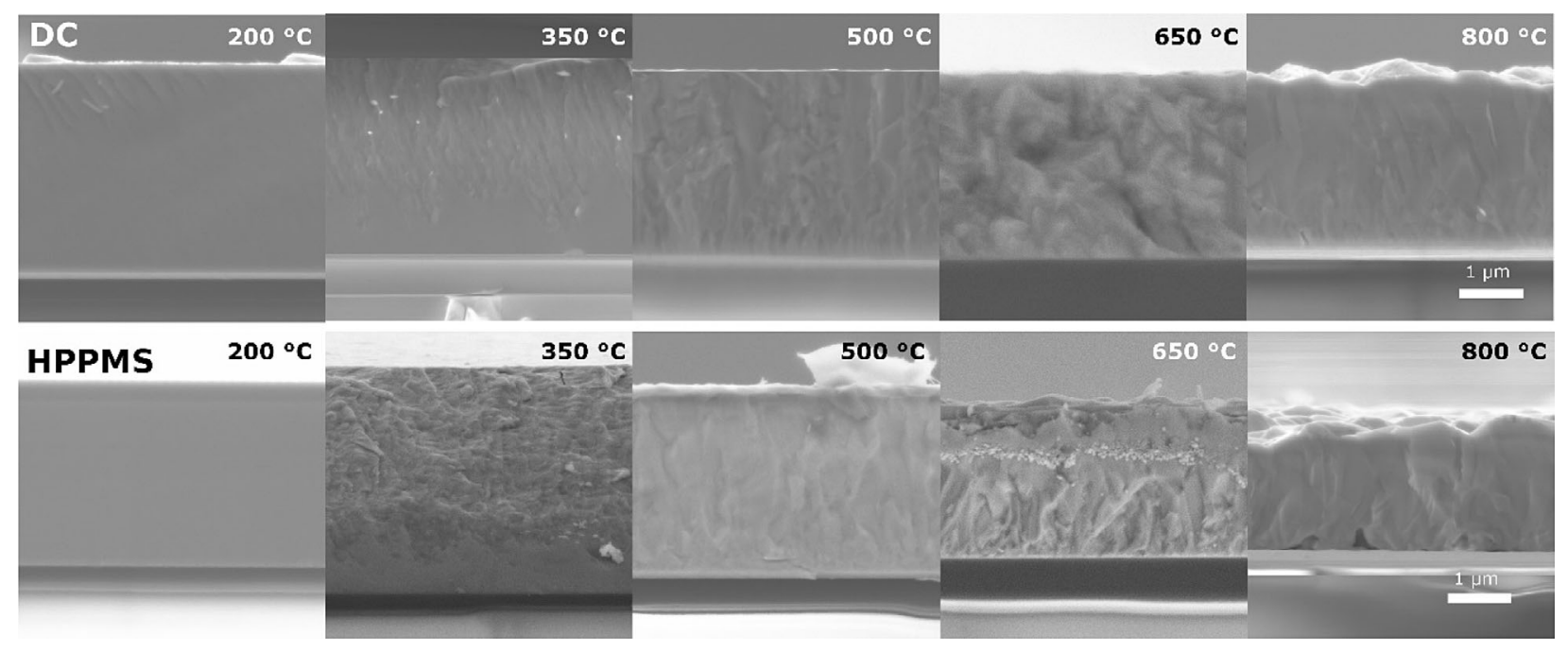

Fig. 4. SEM cross section images of Ge films deposited by DC (top row) and HPPMS (bottom row). Scale bar is identical for all SEM images.

than for the DC deposited one. For Ge, the substrate to melting temperature $\left(T_{m}\right)$ ratio $\left(T_{S} / T_{m}\right)$ is 0.37 at $350^{\circ} \mathrm{C}$. According to the Structure Zone Diagram (SZD), ${ }^{[28,29]}$ this $T_{S} / T_{m}$ should result in a film structure consisting of tightly packed fibrous grains. Since such a structure is absent in the SEM images of the investigated Ge films, this indicates that the structure of Ge films at that $T_{S}$ may be a mixture of crystallites and amorphous phase. The effect of gradual transition from amorphous to crystalline structure, and the co-existence of both phases, for vapor-deposited Ge films for the range of $T_{S}$ of around $300^{\circ} \mathrm{C}$, were reported earlier. ${ }^{[11]}$ For $T_{S}=500$ and $650^{\circ} \mathrm{C}$, a columnar structure starts to be visible. This corresponds to Zone 2 of SZD. ${ }^{[30]}$ The highest investigated temperature gives $T_{S} / T_{m}$ of 0.85 , which places the film structure into Zone 3 of the SZD. Accordingly, film displays grain structures extending through the whole film thickness.

For DC deposition process, film thicknesses ranged from 0.9 to $1.2 \mu \mathrm{m}$ at the thinnest end, to 3.0 to $3.4 \mu \mathrm{m}$ at the thickest end. For HPPMS deposition process, the thickness values ranged from 0.6 to $0.9 \mu \mathrm{m}$, and from 2.2 to $3.0 \mu \mathrm{m}$ for the thinnest and thickest ends, respectively. Thickness values were obtained directly from the SEM film cross sections. The HPPMS sample deposited at $800^{\circ} \mathrm{C}$ appears to be thinnest in general, which can be due to the deposition uniformity due to the placement of this substrate beyond the edge of the target. However, for all other films no clear dependence of the overall film thickness change with respect to $T_{S}$ could be established, indicating that for $T_{S}$ below the Ge melting point the resputtering effect is negligible.

The Scherrer method gives information only on the size of coherent $\mathrm{x}$-ray reflexive domains, and is highly approximative. To get direct information about film structure, grain sizes at the film surface were determined from SEM images for $T_{S}$ of 500,650 , and $800^{\circ} \mathrm{C}$. SEM images of these film surfaces are shown in Figure $5 a$ and $b$, for the DC and HPPMS deposition methods, respectively. For $T_{S}=350{ }^{\circ} \mathrm{C}$, the clustering on the film surface was too fine to quantitatively estimate grain sizes, but it can be assumed that the sizes of the grains observed for $T_{S}=350{ }^{\circ} \mathrm{C}$ are comparable to the crystallite sizes obtained from the Scherrer equation. Values for the crystallite sizes and granulation as a function of $T_{S}$ are shown in Table 2 . Since the grains are of a very irregular shape, determining their size remains qualitative. To compensate for this, clusters were measured in three different ways, as described in the experimental section. The relatively large standard deviation indicates that variation in cluster sizes for the same sample is significant. From the data shown in Table 2 , for $T_{S}=350{ }^{\circ} \mathrm{C}$, the clustering at the film surface was too fine to be possible to objectively estimate grain sizes. Here, the crystallite sizes obtained from the Scherrer equation were used. Table 2 shows values of crystallite sizes and granulation in dependence on $T_{S}$. Since individual grain shapes are very irregular, it leads to the crystallite sizes obtained by the Scherrer method being almost an order of magnitude smaller than the clusters observed by SEM. Since it is unlikely that the additional influences by the FWHM of XRD lines can have such a large effect, it is concluded that the observed clusters are a polymorph structure, and cannot be considered equivalent to coherent reflexive domains. With increasing $T_{S}$ both crystallites and grains increase in size, the difference of which for the $T_{S}$ of 500 and $800{ }^{\circ} \mathrm{C}$ is by factor three to four. There is also a factor of two to three size difference from the thinnest to the thickest parts of the films. For $T_{S}$ of 650 and $800^{\circ} \mathrm{C}$, grain sizes are comparable in size to the film thickness.

\subsection{Thermal Conductivity}

The dependence of thermal conductivity $(\lambda)$ on $T_{S}$ up to $650{ }^{\circ} \mathrm{C}$ and film thickness is shown in Figure $6 \mathrm{a}$ and $\mathrm{b}$ for DC and HPPMS films, respectively. The films deposited at $T_{S}=800^{\circ} \mathrm{C}$ could not be measured due to their highly diffusive surface, even though XRD analysis did show a high degree of crystallization. This means that the problem 


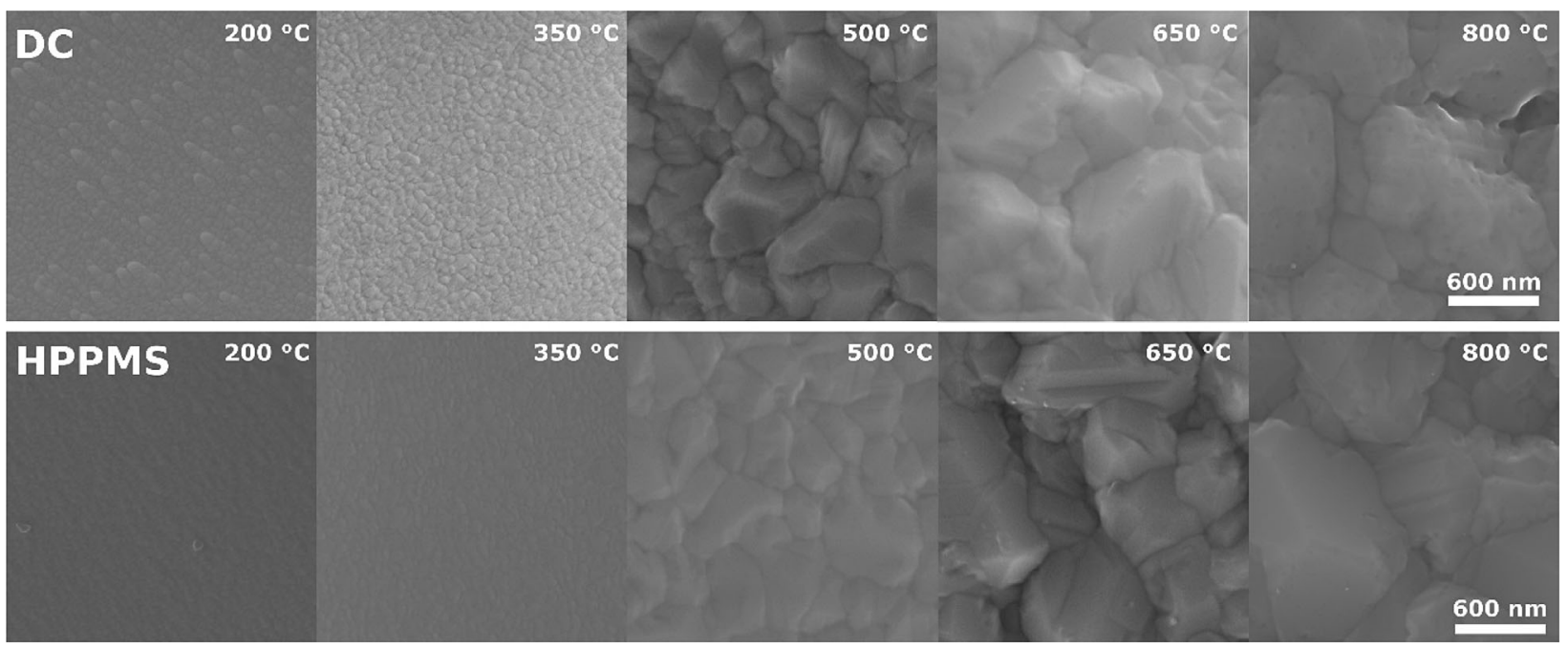

Fig. 5. SEM Ge film surface micrographs for DC power control (top row) and HPPMS (bottom row). Scales are identical for all SEM images.

lies probably on the macroscale, rather than microscale. This is further supported by the fact that for $T_{S}=800^{\circ}$ $\mathrm{C}$ adhesion to the substrate started to be problematic, and films had a white overlay that could not be analyzed by energy-dispersive X-ray spectroscopy (EDX). For $T_{S}<500^{\circ} \mathrm{C}, \lambda$ is an order of magnitude lower compared to the bulk value for $\mathrm{Ge}$ of $60 \mathrm{~W} \mathrm{mK}^{-1}$. For $T_{S}=650^{\circ} \mathrm{C}$ for DC and $500^{\circ} \mathrm{C}$ for HPPMS, the values of $\lambda$ for the thickest parts of the films increase to values close to the bulk value. The anomaly at $T_{S}=650^{\circ} \mathrm{C}$ for HPPMS films is discussed later in relation to electrical resistivity $(\rho)$. The trend toward increasing $\lambda$ values with increasing film thickness was observed for all investigated crystalline Ge films. This trend is, however, not observed for DC and HPPMS amorphous films for $T_{S}=200^{\circ} \mathrm{C}$. That suggests that the $\lambda$ is affected by the film's structural properties, rather than film thickness. The $\mathrm{Ge}$ film deposited at $T_{S}=25^{\circ} \mathrm{C}$ and subsequently annealed at $500^{\circ} \mathrm{C}$ for $150 \mathrm{~min}$, has a $\lambda$ value that is approximately a factor of four lower than the one measured for films deposited directly at $T_{S}=500^{\circ} \mathrm{C}$,
Figure $3 \mathrm{~b}$. On the other hand, corresponding with most of the hot deposited samples, this film does show an increase in $\lambda$ with increasing film thickness. By comparing the variation of $\lambda$ for the annealed sample to the variation of crystallite size, Figure 7 , it is obvious that both values follow a very similar trend with the variation of film thickness, with the leveling of both values for thicknesses $>1 \mu \mathrm{m}$. This confirms that $\lambda$ is closely related to the film structure properties. This can be further confirmed by the fact that the thermal conductivity and crystallite size values for the annealed film are very similar to those for the hot deposited film at $T_{S}=350^{\circ} \mathrm{C}$, Figure $2 \mathrm{a}$ and $\mathrm{b}$. Interestingly, $\lambda$ values show leveling near the substrate edge, where films are thickest, regardless of their actual thickness.

\subsection{Electrical Resistivity}

Electrical resistivity $(\rho)$ of Ge thin films for different $T_{S}$, and its dependence on the different film thicknesses is shown in Figure $6 \mathrm{c}$ and $\mathrm{d}$, for DC and HPPMS, respectively. For both

Table 2. Comparison of the crystallite sizes obtained by the Scherrer method to sizes of the structural clusters measured directly from the SEM images, for different $T_{S}$ and DC sputtering and HPPMS deposition methods.

\begin{tabular}{|c|c|c|c|c|c|}
\hline \multirow{2}{*}{$\begin{array}{l}\text { Substrate temperature } \\
T_{S}\end{array}$} & \multirow{2}{*}{$\begin{array}{l}\text { Scherrer } \\
\text { Size }[\mathrm{nm}]\end{array}$} & \multirow{2}{*}{$\begin{array}{l}\text { Feret's diameter } \\
\quad \text { Size }[\mathrm{nm}]\end{array}$} & \multicolumn{2}{|c|}{ Bounding rectangle } & \multirow{2}{*}{$\begin{array}{c}\text { LIM } \\
\text { Size }[\mathrm{nm}]\end{array}$} \\
\hline & & & Width [nm] & Height $[\mathrm{nm}]$ & \\
\hline \multicolumn{6}{|l|}{ DC } \\
\hline $500^{\circ} \mathrm{C}$ & $47 \pm 15$ & $548 \pm 267$ & $396 \pm 220$ & $500 \pm 258$ & $272 \pm 60$ \\
\hline $650^{\circ} \mathrm{C}$ & $80 \pm 25$ & $843 \pm 251$ & $668 \pm 187$ & $750 \pm 249$ & $388 \pm 23$ \\
\hline $800^{\circ} \mathrm{C}$ & $124 \pm 25$ & 1500 & & & $924 \pm 144$ \\
\hline \multicolumn{6}{|l|}{ HPPMS } \\
\hline $500^{\circ} \mathrm{C}$ & $44 \pm 12$ & $702 \pm 193$ & $511 \pm 124$ & $612 \pm 193$ & $299 \pm 24$ \\
\hline $650^{\circ} \mathrm{C}$ & $79 \pm 18$ & $672 \pm 279$ & $570 \pm 268$ & $569 \pm 196$ & $368 \pm 75$ \\
\hline $800^{\circ} \mathrm{C}$ & $119 \pm 2$ & $889 \pm 301$ & $738 \pm 230$ & $790 \pm 310$ & $654 \pm 124$ \\
\hline
\end{tabular}



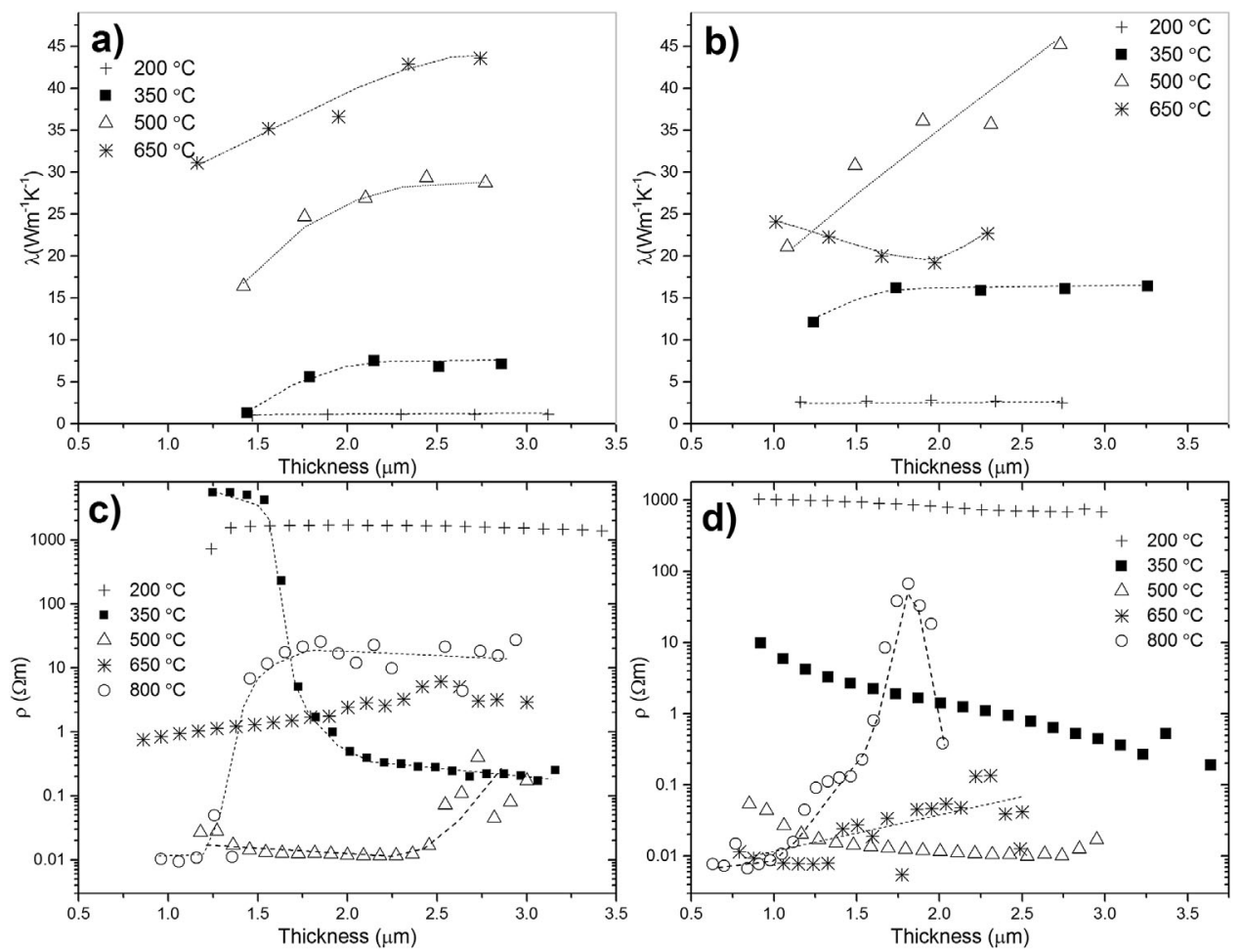

Fig. 6. Comparison of transport properties of Ge films for different $T_{S}$ and thicknesses (a), (b) thermal conductivity, and (c), (d) electrical resistivity values for DC and HPPMS sputtered films. Lines are only to guide the eye.

methods, the electrical resistivity decreases up to five orders of magnitude when increasing $T_{S}$ from 200 to $500^{\circ} \mathrm{C}$. For the amorphous films deposited at $T_{S}=200^{\circ} \mathrm{C}$ for both DC and HPPMS deposition methods, $\rho$ is constant along the whole substrate length. The fact that the same was observed for $\lambda$, indicates that the major factor that affects transport properties in Ge films is crystallization. The $\rho$ values for $T_{S}$ between 200 and $500^{\circ} \mathrm{C}$ remains in the range of $10^{-3}$ to $10^{5} \Omega \mathrm{m}$ typical for semiconductors. An illustrative comparison of measured values to bulk values cannot be given, since $\rho$ of pure Ge is strongly dependent on impurities and can change by several orders of magnitude. ${ }^{[31,32]}$ In this case, however, due to the simultaneous deposition of samples for the same type of power control, the different contamination of individual samples can be excluded.

For $T_{S}$ up to $500^{\circ} \mathrm{C}$, there is a general trend of decreasing $\rho$ values with increasing film crystallinity and thickness. This is particularly pronounced for $\mathrm{DC}, T_{S}=350^{\circ} \mathrm{C}$, where the steep decrease of $\rho$ of about four orders of magnitude corresponds to the film thickness, at which XRD peaks start to appear. For films deposited at $T_{S}$ of $650 \mathrm{C}$ and $800{ }^{\circ} \mathrm{C}$, there is a reverse in this trend, where $\rho$ shows a tendency toward higher values with increasing $T_{S}$ and film thickness. This trend reverse for high $T_{S}$ can be also due to structural effects that affect the semiconductor band gap, and consequently $\rho$. Impurity and defect-induced changes in carrier scattering can influence $\rho$ significantly in semiconductors. The trend for the $\rho$ variation is clear enough that it would be reasonable to consider an electronic structure characteristic that, for the higher $T_{S}$, counters the improvement of the transport properties due to the increased degree of crystallization.

\section{Discussion}

From the presented data, it is apparent that the crystallization of magnetron sputtered Ge thin films is a process that requires high substrate temperature. The annealing of as-deposited amorphous Ge films induces formation of crystallites to a size of $\approx 10 \mathrm{~nm}$. For $T_{S} \geq 500^{\circ} \mathrm{C}$, SEM of the film the surface shows formation of grains that are an order of magnitude larger than by XRD detected crystallites. The systematic increase in size of both crystallites and grains is detected also with increasing film thickness for all investigated crystalline films. While films deposited at $T_{S}=200{ }^{\circ} \mathrm{C}$ are amorphous, the diffractograms for films deposited at $T_{S}=350^{\circ} \mathrm{C}$ show clear indications of crystalline Ge. The transition from amorphous to crystalline structure can be observed in the film deposited by DC sputtering at $T_{S}=350^{\circ} \mathrm{C}$. Films of thicknesses $<1.5 \mu \mathrm{m}$ appear to be amorphous, but crystallize for larger thicknesses, Figure 2a. Since this behavior is not observed for films deposited by HPPMS at the same $T_{S}$, their improved crystallization is probably due to the higher energy of depositing particles caused by more and higher ionization. The phase change is also reflected by the change of $\rho$, as shown on Figure 6c. This suggests that for magnetron sputtered Ge films, there is possibly only a very narrow range of $T_{S}$ where one could expect to have a mixture of 


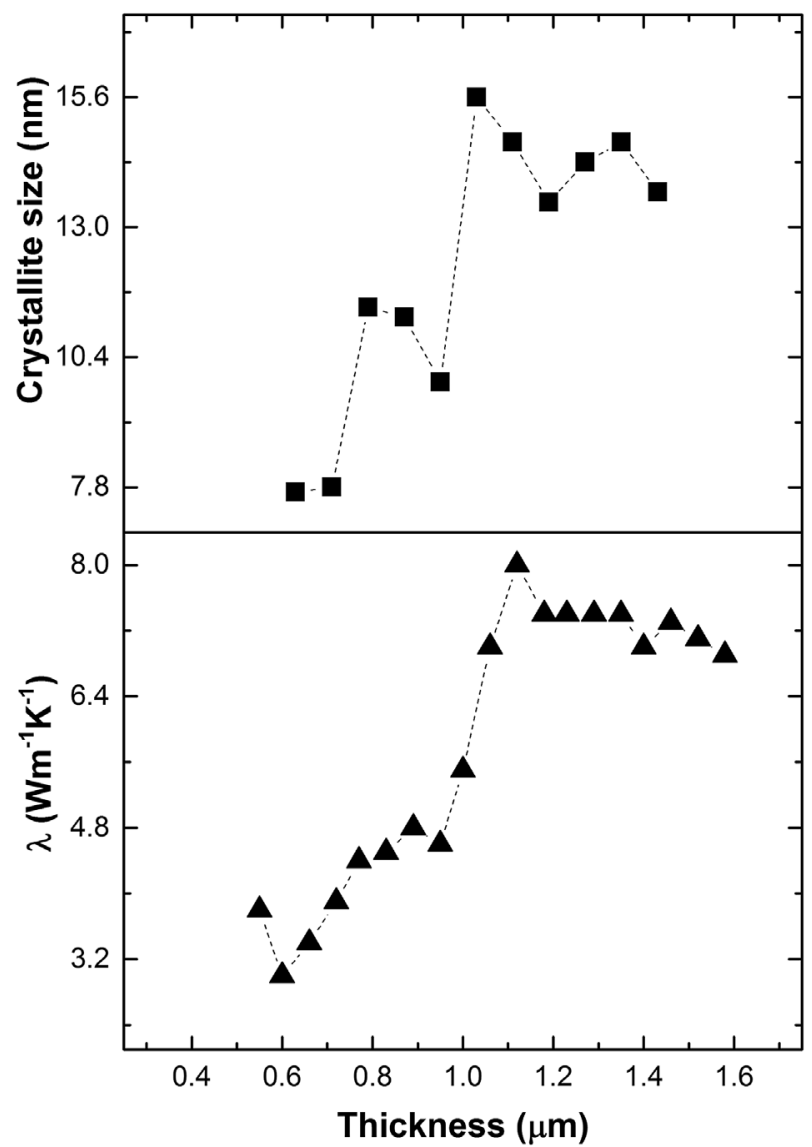

Fig. 7. (a) Crystallite size determined from (111) and (220) diffraction peaks, and (b) thermal conductivity change in relation to film thickness for Ge film deposited at $25^{\circ} \mathrm{C}$ and annealed at $500^{\circ} \mathrm{C}$.

amorphous and crystalline phases. For the annealed film deposited at $T_{S}=25^{\circ} \mathrm{C}$, the presence of the amorphous phase cannot be completely excluded. These results show that there is similar behavior in Ge film crystallization for sputtered and vapor-deposited Ge films. For the latter, according to earlier reports crystallization could be achieved only by deposition at temperatures $>250{ }^{\circ} \mathrm{C}$, with a completely polycrystalline structure appearing only for deposition temperatures $>500{ }^{\circ} \mathrm{C}^{[33]}$ Gradual transitions between mixtures of amorphous and crystalline phases for Ge were also reported. ${ }^{[11]}$

By correlating, the measured transport properties of $\mathrm{Ge}$ films to their structure, it is apparent that increased crystallization favors increased thermal and electrical conductivities up to $T_{S} \leq 500{ }^{\circ} \mathrm{C}$. While for $T_{S} \leq 500{ }^{\circ} \mathrm{C} \lambda$ is up to an order of magnitude lower compared to the bulk Ge value, for $T_{S} \geq 650^{\circ} \mathrm{C}$ the values for $\lambda$ approach those for the bulk Ge. For electrical conductivity, it is difficult to make a comparison between bulk and thin film values, because of the strong dependence of semiconductor $\rho$ on impurities and defects in the material. Any significant direct influence of the thickness effect on the investigated transport properties can be excluded by observing films for $T_{S}=200{ }^{\circ} \mathrm{C}$, which are completely amorphous and which show marginal or no change in either $\lambda$ or $\rho$ with the changing thickness.

For the trend inversion of the $\lambda$ and $\rho$ dependence on $T_{S}$ and film thickness for the two highest $T_{S}$, it can be observed that this inversion is even more pronounced for $T_{S}=800{ }^{\circ} \mathrm{C}$ than for $T_{S}=650{ }^{\circ} \mathrm{C}$. Comparing this to the trends of the values shown in Table 2, it can be observed that the ratios between surface grain sizes and crystallite sizes of the films increase abruptly starting from $T_{S}=650^{\circ} \mathrm{C}$ and becoming even more pronounced for $800{ }^{\circ} \mathrm{C}$. This can be correlated to earlier reports ${ }^{[15,34]}$ that the carrier dispersion on crystallite and grain boundaries may have a significant influence on their mean free path, and that a carrier mean free path being larger than film thickness or sample dimensions can also imply a reduction in transport properties. X-ray diffractograms show no detectable systematic peak shifts for different $T_{S}$ (Figure 1 ). This indicates the absence of intrinsic stresses in the films that could introduce changes in transport properties according to earlier reports.

\section{Conclusions}

In this study, Ge thin films were deposited in the form of variable thickness wedges by DC sputtering and HPPMS deposition methods for different substrate temperatures. The optimization of deposition parameters to achieve the highest thermal and electrical conductivity was investigated and correlated to film crystallization evolution. The comparison of film structure for two deposition methods shows using HPPMS instead of DC for improved crystallization and lower electrical resistivity could be established for the parameters $T_{S}=350{ }^{\circ} \mathrm{C}$ and film thickness $<2 \mu \mathrm{m}$. Films deposited at $T_{S}=500^{\circ} \mathrm{C}$ show a significantly higher degree of crystallization compared to amorphous films deposited at lower temperatures and subsequently annealed at $500{ }^{\circ} \mathrm{C}$. Post-annealing is, thus proved to be inadequate for inducing crystallization in magnetron sputtered Ge thin films. The analysis shows that crystallization is strongly influenced by film thickness and substrate temperature, and increases with the increasing values of both of those parameters. The thermal and electrical conductivities increase with the increasing crystallization and increasing film thickness up to $T_{S}=500{ }^{\circ} \mathrm{C}$, after which the trend is reversed probably due to the opposing effects of structure crystallization and clustering.

We conclude that in order to obtain pure Ge coatings with the highest thermal conductivity and lowest electrical resistivity by magnetron sputtering, it is optimal to do hot depositions at a substrate temperature of around $500{ }^{\circ} \mathrm{C}$ for film thickness between 2 and $2.5 \mu \mathrm{m}$. For higher temperatures, film transport properties deteriorate rapidly, while for thicknesses $>2.5 \mu \mathrm{m}$ there are also indications of erratic behavior of measured transport properties regardless of the type of the sputter power control. 
[1] W.-J. Lee, J. Sharp, G. A. Umana-Membreno, J. Dell, L. Faraone, Mater. Sci. Semicond. Process. 2015, 30, 413.

[2] B. Bitnar, Semicond. Sci. Technol. 2003, 18, S221.

[3] B. Abeles, D. S. Beers, G. D. Cody, J. P. Dismukes, Phys. Rev. 1962, 125, 44.

[4] B. Yu, M. Zebarjadi, H. Wang, K. Lukas, H. Wang, D. Wang, C. Opeil, M. Dresselhaus, G. Chen, Z. Ren, Nano Lett. 2012, 12, 2077.

[5] M. Zebarjadi, G. Joshi, G. Zhu, B. Yu, A. Minnich, Y. Lan, X. Wang, M. Dresselhaus, Z. Ren, G. Chen, Nano Lett. 2011, 11, 2225.

[6] S. de Gironcoli, P. Giannozzi, S. Baroni, Phys. Rev. Lett. 1991, 66, 2116.

[7] A. Katre, R. Drautz, G. K. H. Madsen, J. Phys-Condens. Mat. 2013, 25, 365403.

[8] N. Mingo, D. Hauser, N. P. Kobayashi, M. Plissonnier, A. Shakouri, Nano Lett. 2009, 9, 711.

[9] R. Grigorovici, Mater. Res. Bull. 1968, 3, 13.

[10] K. L. Chopra, S. K. Bahl, Phys. Rev. B 1970, 1, 2545.

[11] F. Evangelisti, M. Garozzo, G. Conte, J. Appl. Phys. 1982, 53, 7390.

[12] C. Bundesmann, R. Feder, R. Wunderlich, U. Teschner, M. Grundmann, H. Neumann, Thin Solid Films 2015, $589,487$.

[13] B. Cunningham, J. O. Chu, S. Akbar, Appl. Phys. Lett. 1991, 59, 3574.

[14] C. Suryanarayana, I. Seki, A. Inoue, J. Non-Cryst. Solids 2009, 355, 355.

[15] J. Alvarez-Quintana, J. Rodríguez-Viejo, F. X. Alvarez, D. Jou, Int. J. Heat Mass Transfer 2011, 54, 1959.

[16] J. W. Vandersande, C. Wood, Contemp. Phys. 1986, $27,117$.

[17] H. Stein, D. Naujoks, D. Grochla, C. Khare, R. Gutkowski, S. Grützke, W. Schuhmann, A. Ludwig,
Phys. Status Solidi A 2015, 212, 2798.

[18] C. Krywka, M. Paulus, C. Sternemann, M. Volmer, A. Remhof, G. Nowak, A. Nefedov, B. Poter, M. Spiegel, M. Tolan, J. Synchrotron Radiat. 2006, 13,8 .

[19] J. Schindelin, C. T. Rueden, M. C. Hiner, K. W. Eliceiri, Mol. Reprod. Dev 2015, 82, 518.

[20] T. Sigurd, H. Sven, L. Alfred, Sci. Technol. Adv. Mater. 2011, 12, 54206.

[21] S. Dilhaire, G. Pernot, G. Calbris, J. M. Rampnoux, S. Grauby, J. Appl. Phys. 2011, 110, 114314.

[22] D. G. Cahill, H. E. Fischer, T. Klitsner, E. T. Swartz, R. O. Pohl, J. Vac. Sci. Technol. A 1989, 7, 1259.

[23] R. Venkatraman, J. C. Bravman, J. Mater. Res. 1992, 7, 2040.

[24] C. V. Thompson, J. Mater. Res. 1993, 8, 237.

[25] M. Birkholz, P. F. Fewster, C. Genzel, Thin film analysis by $\mathrm{X}$-ray scattering, Wiley-VCH, John Wiley, distributor, Weinheim, Chichester 2006, Ch 3.

[26] G. Janssen, Thin Solid Films 2007, 515, 6654.

[27] I. C. Noyan, T. C. Huang, B. R. York, Crit. Rev. Solid State Mater. Sci. 1995, 20, 125.

[28] J. A. Thornton, J. Vac. Sci. Technol. 1974, 11, 666.

[29] A. Anders, Thin Solid Films 2010, 518, 4087.

[30] J. A. Thornton, J. Vac. Sci. Technol. 1975, 12, 830.

[31] H. Fritzsche, Phys. Rev. 1955, 99, 406.

[32] F. R. Allen, C. J. Adkins, Philos. Mag. 1972, 26, 1027.

[33] V. Sorianello, L. Colace, M. Nardone, G. Assanto, Thin Solid Films 2011, 519, 8037.

[34] L. H. Nguyen, H. Riegel, M. Asen-Palmer, E. Gmelin, Physica B 1996, 218, 248. 